\title{
A PESQUISA QUE FAZ DIFERENÇA
}

\section{RESUMO}

Os pesquisadores da administração lamentam o fato de que seu trabalho tenha tão pouco impacto na prática gerencial. Os gerentes, por sua vez, procuram conhecimento que possa ajudá-los a melhorar a performance organizacional, mas raramente consultam os trabalhos universitários - freqüentemente tidos como incompreensíveis e irrelevantes para os desafios cotidianos. Para que a pesquisa em administração possa fazer diferença para os gerentes são necessárias parcerias mutuamente benéficas que envolvam os gerentes e os pesquisadores e que sejam apoiadas por suas respectivas organizações. Ilustramos a importância da pesquisa da administração relevante para a prática valendo-se de quatro importantes contribuições, juntos, estes casos não somente demonstram como esse tipo de parceria pode produzir conhecimento relevante para a prática, mas também promovem insights para aumentar a probabilidade de ocorrência de encontros produtivos.

\section{Eric W. Ford}

Pennsylvania State University

\section{W. Jack Duncan}

University of Alabama

\section{Arthur G. Bedeian}

Louisiana State University

Peter M. Ginter

University of Alabama

Matthew D. Rousculp

University of Alabama

\section{Alice M. Adams}

University of Alabama

\begin{abstract}
Management researchers lament the fact that their work has so little impact on management practice. Practicing managers, so it is claimed, search for knowledge that will help them improve organizational performance but rarely consult the work of university-based researchers - work that they often find incomprehensible and irrelevant to their day-to-day challenges. We contend that for management research matter to managers it is required the creation of mutually beneficial partnerships involving managers and researchers, as well as the support of their organizations. We illustrate the importance of practice-relevant management research by drawing on four important contributions. Together these illustrations not only demonstrate how this kind of partnership can yield practice-relevant knowledge, but also provide insights into enhancing the likelihood that productive encounters will occur.
\end{abstract}

PALAVRAS-ChAVE Pesquisa em Administração, ciência da administração, administração de performance, instituto de pesquisa e estilos gerenciais.

KEY WORDS Management Research, management science, performance Management, Research institutes, Management styles 


\section{INTRODUÇÃo}

Os executivos valorizam o conhecimento como uma fonte potencial de vantagem competitiva. Infelizmente, a busca por conhecimento prático que seja de interesse raramente resulta em parcerias entre os executivos e os pesquisadores acadêmicos. Pelo contrário, essa busca culminou na criação de uma indústria de consultoria de US\$ 15 bilhões, apenas nos Estados Unidos. Outro bilhão de dólares é gasto por ano pelos executivos em livros de negócios, poucos dos quais escritos por pesquisadores que realizam investigações nas universidades. Em 2001, somente 10\% dos "Top Business Books", lista elaborada pela Business Week, eram de autoria de acadêmicos. E o mesmo se repetiu em 2002.

Os pesquisadores da área de administração lamentam o fato de que seu trabalho tenha um impacto tão pequeno na prática gerencial. Eles afirmam que muitos executivos estão mais interessados em soluções rápidas para problemas imediatos do que em soluções de longo prazo voltadas para a melhoria da performance organizacional. Apontando os números de vendas dos livros de negócios, os pesquisadores sustentam que, entre os executivos, há quase uma obsessão por modas e modismos. Eles também advertem que tais modas e modismos podem causar mais danos do que benefícios, pois obscurecem conceitos estabelecidos de management e aplicações que têm potencial de melhorar o desempenho das organizações. Esses mesmos pesquisadores ainda argumentam que, para se alcançar uma maximização de lucros, os resultados de seus esforços não deveriam ser direcionados para os mundanos acontecimentos de dia-a-dia da vida do executivo, mas que, em vez disso, deveriam ser usados para resolver os desafios de management de longo prazo.

\section{PESQUISA DE ADMINISTRAÇÃO QUE FAZ DIFERENÇA PARA OS EXECUTIVOS}

Os executivos também têm razão! Em seu discurso presidencial para a Academy of Management, questionado sobre "o que aconteceria se a Academy realmente importasse?", Donald Hambrick insinuou que ela não faz muita diferença para os executivos porque "todo mês de agosto vimos aqui para trocar idéias; durante o resto do ano lemos papers dos colegas em nosso journal e escrevemos nossos próprios papers para que possamos ter audiência no próximo mês de agosto: é um círculo vicioso". Não há, porém, nenhuma razão $a$ priori para que a disseminação da pesquisa de administração continue nesse tipo de estado incestuoso. Considerando que uma das dúvidas mais freqüentes diz respeito ao fato de as pesquisas serem ou não direcionadas para a melhoria das práticas, seguramente algumas delas deverão ter relevância no mundo real. E, de fato, há muitos exemplos sobre como executivos acessaram e se beneficiaram da pesquisa de administração, assim como de pesquisadores que tanto responderam aos desafios reais que os executivos enfrentam, quanto se valeram de suas próprias experiências para investigar esses desafios.

Para ilustrar, J. T. Carney demonstra como o presidente da Sears, Roebuck, tornou-se um executivo que coloca as "mãos na massa". Roebuck gostava de conversar com os empregados na seção de encomendas pelo correio, investigando o que eles pensavam sobre seus trabalhos e oferecendo sugestões para ajudá-los. Em seu escritório em Chicago, porém, sentia-se fora de contato com o campo de operações. Então ele instruiu James Worthy, um de seus "rapazes brilhantes" da área de pessoal, para que "encontrasse um meio de me manter informado dessa parte importante de meu trabalho". Trabalhando com estudiosos de várias disciplinas e instituições, baseando-se nos surveys da força de trabalho realizados na Sears sob o patrocínio de Roebuck, Worthy escreveu os clássicos artigos sobre a influência da estrutura organizacional no moral do pessoal, que foram publicados na American Sociological Review e na Harvard Business Review.

De maneira complementar, Worthy observou que a publicação dos resultados dos surveys realizados na Sears teve um impacto significativo sobre o futuro pensamento administrativo, influenciando as pesquisas de acadêmicos como Rensis Likert, Wright Bakke, Eliot Jacques, Douglas McGregor, William Newman e Peter Drucker. Além disso, esses resultados possibilitaram, a Worthy, a participação em conferências em Chicago, Columbia, Harvard, Michigan, MIT, Stanford e outras universidades, reforçando a conexão indústria /universidade. Dessa forma, a preocupação de um "executivo afastado da linha de frente" gerou uma solução inovadora que continuou a influenciar a pesquisa de administração.

O que aconteceria se mais organizações empreendessem e utilizassem pesquisas relevantes para a prática gerencial? O que aconteceria se mais pesquisadores de universidades pudessem encontrar organizações tão receptivas quanto a Sears para se engajarem nesse 
tipo de pesquisas (e patrociná-las), bem como para utilizar os resultados a fim de melhorar suas operações? Quanto dinheiro as organizações poderiam poupar em honorários de consultoria e na inflexível busca de soluções rápidas? Quão valioso seria para os pesquisadores saberem que realmente afetam de maneira positiva as práticas gerenciais?

Refletindo sobre tais questões, este artigo ilustra a importância de pesquisas práticas de administração relevantes para as práticas gerenciais, tomando como base quatro importantes contribuições para a compreensão gerencial, contribuições estas que foram inspiradas pelas experiências organizacionais de um grupo de executivos investigadores e de pesquisadores curiosos. Cada um dos casos que apresentamos coloca novas provocações, e todas as parcerias discutidas foram mais acidentais do que planejadas. O desafio é reconhecer meios de aumentar a probabilidade de produzir parcerias entre executivos e pesquisadores que sejam mutuamente benéficas e que eles se reforcem. Baseando nossas sugestões nas lições aprendidas em cada caso, e recorrendo às descobertas relacionadas à transferência do conhecimento para a prática, oferecemos uma agenda para enfrentar esse desafio.

\section{ORIGENS DE IDÉIAS GERENCIAIS INFLUENTES: UM PONTO DE PARTIDA}

Onde podemos encontrar a gênese de idéias que influenciam a teoria e a prática do management? Um ponto de partida lógico é o exame da vida dos indivíduos que desenvolveram e conduziram pesquisas teóricas e que, por sua vez, deram origem às idéias que têm influenciado as práticas gerenciais contemporâneas. Identificamos duas fontes principais para esse tipo de informação: as biografias e, ainda mais válidas para nossos propósitos, as autobiografias.

\section{Insights biográficos}

A geração de insights sobre a vida e as idéias de membros de grupos ilustres por meio do estudo de suas características biográficas comuns tem uma longa tradição na sociologia da ciência. Estudos biográficos revelaram insights sobre a vida de premiados com o Nobel, de presidentes dos Estados Unidos, atletas olímpicos, mestres do xadrez, psicólogos e estrelas de cinema. Talvez duas das mais conhecidas biografias da literatura de negócios sejam o Golden Book of
Management, de Lyndall Urwick, e uma antiga publicação de Urwick e Brech em que também se enfatizava a importância das biografias no entendimento da evolução do pensamento gerencial.

Muito do interesse de Urwick na pesquisa biográfica provinha do desejo de entender o management, assim como outros campos, como um fluxo cumulativo de idéias. O mesmo argumento foi colocado mais recentemente por Witzel (2001) no prefácio de seu dicionário biográfico de management, quando declarou: "Chegamos à conclusão de que nosso principal interesse não eram os executivos como indivíduos, mas o management como um conjunto de idéias e práticas. Queríamos verificar se poderíamos utilizar o estudo das pessoas para saber mais sobre suas idéias" (p. x).

\section{Insights autobiográficos}

Devido à sua dependência de fontes secundárias, as investigações biográficas fornecem insights limitados sobre a origem das idéias. As autobiografias, por sua vez, como exercícios de auto-exemplificação, oferecem um meio singular de examinar os bastidores e encontrar insights valiosos para o entendimento das experiências pessoais de seus autores, assim como a conexão entre suas experiências e o desenvolvimento de seus interesses e idéias. As autobiografias de vários líderes da área de negócios, por exemplo, permitem que eles descrevam, com suas próprias palavras, os fatos e as pessoas que moldaram suas vidas e que os trouxeram às posições de liderança no setor em que atuam.

O valor das autobiografias é realçado pelo fato de que os autobiógrafos são os "reais atores de um papel dual de participação-observação", tendo um acesso privilegiado a seus próprios pensamentos internos. Por fornecer informação auto-relevante direta e que não é de segunda mão, o autobiógrafo é mais qualificado do que qualquer um para documentar pensamentos e experiências que não são acessíveis por meio de outras fontes. Pesquisas indicam que as considerações autobiográficas sobre os episódios ou eventos mais importantes para o autor são tipicamente mais exatas do que a reunião de experiências mais gerais e emocionalmente neutras.

Isso não quer dizer, no entanto, que não há problemas potenciais com o uso de dados autobiográficos. As autobiografias podem, por exemplo, ser laudatórias ou imprecisas. Alguns detalhes podem ser esquecidos ou mal relembrados, e detalhes completamente novos podem tomar espaço na memória do autor. 


\section{Autobiografias de pesquisadores da administração}

Os seis volumes seriados de Bedeian, intitulados Management Laureates: A Collection of Autobiographical Essays, oferecem uma base de dados única para o estudo das autobiografias de uma amostra de indivíduos que fizeram contribuições significativas para o campo do management. Incluídos nessas séries estão indivíduos que participaram do desenvolvimento de teorias que favoreceram a inovação das práticas gerenciais. Tais colaboradores foram selecionados para a série porque provocaram um impacto significativo sobre esse campo e porque são contínuos observadores da pesquisa e prática do management.

Examinamos as autobiografias de 52 laureados que compõem as séries de Bedeian para identificar experiências, eventos e pessoas que influenciaram a formulação de suas idéias sobre o management. Tendo em vista nosso objetivo, de ilustrar a importância de pesquisas relevantes para a prática do management, queríamos examinar a extensão na qual as próprias experiências organizacionais dos laureados e suas interações com a prática dos executivos tinham ajudado a moldar suas idéias e pesquisas. A análise confirmou que, ao discutirem as influências que sofreram em suas carreiras, os laureados evocavam lugares específicos, nos quais ocorreram eventos relevantes, assim como indivíduos que influenciaram seu pensamento.

\section{Prática e pesquisa de administração}

O Quadro 1 apresenta uma lista de quatro importantes áreas de pesquisa prática relevante que tanto resultaram das experiências organizacionais dos laureados, quanto evoluíram a partir das interações entre eles e executivos práticos. Cada área é discutida com algum nível de detalhamento para ilustrar os benefícios que podem advir, para executivos e pesquisadores, desse tipo de pesquisa baseada na realidade. As lições aprendidas com cada experiência também foram brevemente destacadas.

\section{HIGH-RELIABILITY ORGANIZATIONS, DIMINUIÇÃO DE RISCOS E MARINHA NUCLEAR}

A moderna tecnologia vem originando novas formas organizacionais. A administração, como disciplina formal, está sendo constantemente obrigada a atualizar suas prescrições à luz da mudança das condições ambientais. Felizmente, as organizações evoluíram para lidar com as demandas crescentes de ambientes cada vez mais complexos. Atualmente, um tipo especial de organização, a high-reliability organization (HRO), tem criado desafios especiais para aqueles que a administram. Essas organizações "operam sob condições muito difíceis, mas apresentam menos acidentes do que seria esperado". As usinas de energia nuclear são HROs, assim como os sistemas de controle de tráfego aéreo e os submarinos nucleares. Os portaaviões nucleares têm sido um dos mais importantes campos para a pesquisa de HRO. Admiral Thomas Mercer, o segundo-capitão da USS Carl Vinson, entrou em contato com o trabalho que Karlene Roberts e seus colegas tinham feito sobre a introdução dos esquadrões F-14 na marinha de guerra norte-americana do Pacífico. O conhecimento que Admiral Mercer obteve sobre esse trabalho foi decisivo para seu patrocínio de uma pesquisa baseada nos porta-aviões nucleares como protótipos de HROs.

O primeiro-capitão da Carl Vison era também o primeiro-comandante do esquadrão F-14 e estava prestes a completar sua tese de doutorado em Física. Ao procurar uma literatura para a pesquisa que pudesse ser útil para assegurar a presteza operacional do esquadrão, deparou-se com a comunicação de pesquisa de Karlene Roberts e Charles O'Reilly. Mais tarde, quando Admiral Mercer expressou suas preocupações em relação à administração de tecnologias perigosas, o primeiro-capitão sugeriu-lhe contatar Roberts. Quando Mercer e Roberts se encontraram, conversaram sobre a possibilidade de conduzir uma pesquisa em sua embarcação sobre os meios pelos quais as organizações aprendem a mitigar riscos. Esse encontro e a pesquisa que se seguiu mudaram dramaticamente a vida de Roberts.

Roberts literalmente "escreveu o livro" sobre como administrar a mais complexa organização imaginável: um porta-aviões nuclear. Além disso, essa não era apenas uma organização inacreditavelmente complexa, mas também demandava algo próximo da perfeita confiabilidade. HROs são "extremamente rígidas quando nada interessante está acontecendo", mas, se uma batalha ou uma simulação de batalha se desenvolve, "a flexibilidade assume o posto, confia-se que as pessoas farão seu trabalho da maneira que têm sido treinadas e a função do comandante é ter em mãos a visão do que acontece. O microgerenciamento não é somente insatisfatório em tais situações: ele pode ser desastroso". Os resultados da pesquisa de Roberts têm sido 
Quadro 1 - Exemplos de pesquisas relevantes para a prática.

\begin{tabular}{|c|c|c|c|c|}
\hline $\begin{array}{l}\text { ORGANIZAÇÃO } \\
\text { NA QUAL A } \\
\text { PESQUISA SE } \\
\text { ORIGINOU }\end{array}$ & $\begin{array}{c}\text { PESSOA QUE } \\
\text { SUGERIU OU } \\
\text { PATROCINOU A } \\
\text { PESQUISA }\end{array}$ & $\begin{array}{l}\text { PESQUISA } \\
\text { GERADA }\end{array}$ & $\begin{array}{l}\text { INDIVÍDUO } \\
\text { QUE } \\
\text { CONDUZIU A } \\
\text { PESQUISA }\end{array}$ & $\begin{array}{l}\text { SIGNIFICÂNCIA } \\
\text { DA PESQUISA }\end{array}$ \\
\hline $\begin{array}{l}\text { United States } \\
\text { Navy - USS Carl } \\
\text { Vinson }\end{array}$ & $\begin{array}{l}\text { Admiral Thomas } \\
\text { Mercer, Segun- } \\
\text { do-Capitão da } \\
\text { Carl Vison }\end{array}$ & $\begin{array}{l}\text { Desde } 1987 \text {, a pesquisa é utili- } \\
\text { zada para prática do definido e } \\
\text { refinado gerenciamento das } \\
\text { HROs, incluindo como essas for- } \\
\text { mas organizacionais são estru- } \\
\text { turadas, mitigam riscos etc }\end{array}$ & $\begin{array}{l}\text { Karlene } \\
\text { H. Roberts }\end{array}$ & $\begin{array}{l}\text { Ajuda no entendimento de um im- } \\
\text { portante e crescente tipo de orga- } \\
\text { nização que opera sob condições } \\
\text { adversas, mas precisa ter um nú- } \\
\text { mero nulo de acidentes. Exemplos } \\
\text { incluem centros de controle de trá- } \\
\text { fego aéreo, geração de energia nu- } \\
\text { clear, submarinos, porta-aviões e } \\
\text { salas de emergência de hospitais }\end{array}$ \\
\hline $\begin{array}{l}\text { Three Mile Island } \\
\text { Nuclear Plant }\end{array}$ & $\begin{array}{l}\text { Cora Marrett - } \\
\text { Funcionária do } \\
\text { governo que diri- } \\
\text { giu o estudo do } \\
\text { desastre de } \\
\text { Three Mile Island }\end{array}$ & $\begin{array}{l}0 \text { estudo gerou reconhecimento } \\
\text { de que os indivíduos criam riscos } \\
\text { catastróficos que não podem ser } \\
\text { administrados. Sugere que "aci- } \\
\text { dentes normais" acontecem em } \\
\text { todos os sistemas, mas quando } \\
\text { estes são relativamente pequenos } \\
\text { e falham, os danos podem ser } \\
\text { contidos. Já quando os sistemas } \\
\text { se tornam maiores e mais inter- } \\
\text { dependentes, falhas irreparáveis } \\
\text { podem ocorrer }\end{array}$ & $\begin{array}{l}\text { Charles } \\
\text { Perrow }\end{array}$ & $\begin{array}{l}\text { Falhas irreparáveis de sistemas, tais } \\
\text { como o desastre da Challenger e o } \\
\text { vazamento químico da Union } \\
\text { Carbide Bhopal, Índia, aceleraram } \\
\text { a preocupação com a urgência de } \\
\text { "pensar o impensável", "administrar } \\
\text { o inesperado" e obter uma melhor } \\
\text { apreciação das necessidades de } \\
\text { uma crise gerencial }\end{array}$ \\
\hline Rolls-Royce & $\begin{array}{l}\text { Barney Mathias, } \\
\text { Diretor de } \\
\text { Pessoal }\end{array}$ & $\begin{array}{l}\text { Observações do processo pelo } \\
\text { qual os executivos decidem fa- } \\
\text { zer mudanças que mais tarde se } \\
\text { tornarão escolha de perspectiva } \\
\text { estratégica. Essa abordagem en- } \\
\text { fatiza a importância dos executi- } \\
\text { vos, da legitimidade de sua parti- } \\
\text { cipação no desenvolvimento de } \\
\text { arranjos organizacionais, e nega } \\
\text { que as questões estruturais sejam } \\
\text { problemas puramente técnicos }\end{array}$ & John Child & $\begin{array}{l}\text { Controvérsia contínua entre os que } \\
\text { defendem que "os executivos fazem } \\
\text { diferença" no sucesso ou falha de } \\
\text { uma organização e os que sugerem } \\
\text { que a sobrevivência organizacional } \\
\text { e o sucesso resultam mais da sorte } \\
\text { e do acaso do que das escolhas } \\
\text { gerenciais }\end{array}$ \\
\hline $\begin{array}{l}\text { Rand Corporation } \\
\text { and Lockheed } \\
\text { Aircraft } \\
\text { Corporation }\end{array}$ & $\begin{array}{l}\text { Robert Gross, } \\
\text { CEO da } \\
\text { Lockheed }\end{array}$ & $\begin{array}{l}\text { Exames da miopia organizacio- } \\
\text { nal baseados na experiência da } \\
\text { Rand e de problemas relaciona- } \\
\text { dos com o gerenciamento de } \\
\text { organizações diante de descon- } \\
\text { tinuidades ambientais }\end{array}$ & H. Igor Ansoff & $\begin{array}{l}0 \text { processo decisório estratégico efe- } \\
\text { tivo e a formulação estratégica per- } \\
\text { manecem sendo a mais básica de } \\
\text { todas as questões que os executi- } \\
\text { vos devem fazer e responder para a } \\
\text { satisfação dos acionistas. } 0 \text { envolvi- } \\
\text { mento com essas questões culmi- } \\
\text { nou em um dos mais influentes li- } \\
\text { vros sobre estratégia corporativa }\end{array}$ \\
\hline
\end{tabular}


aplicados no processo decisório de pilotos da aviação comercial, bombeiros, médicos de salas de emergência e negociadores da polícia.

O trabalho de Roberts ensina-nos duas importantes lições sobre a pesquisa da administração que importa para os executivos.

Primeiro, a pesquisa relevante para a prática tem mais probabilidade de ocorrer quando há uma "predisposição" para colaborar. Admiral Mercer foi informado sobre os benefícios potenciais da pesquisa que mitiga riscos porque um oficial amigo seu, buscando orientação acadêmica que pudesse resolver problemas reais, recomendou Roberts. Nas palavras de Roberts, ele "estava buscando na estante uma pesquisa que pudesse ajudá-lo". Além disso, a experiência pessoal de Roberts em seu trabalho na usina nuclear da Pacific Company's Diablo Canyon tornou-a atenta aos desafios singulares da gerência das HROs.

Segundo, a pesquisa relevante para a prática pode requerer que os pesquisadores deixem seus campos confortáveis e familiares e que os executivos estejam dispostos a romper o invólucro e permitir o acesso a contextos de pesquisa aparentemente inacessíveis. Roberts, por exemplo, foi desencorajada ao ouvir queixas sobre "deixar uma equipe de pesquisa a bordo de um navio durante a organização das tropas para o combate". Mais desafiador ainda foi o ato do Congresso, que proibia mulheres de participarem de exercícios militares no mar. Como Roberts observou, entretanto, um "oficial da Marinha sugeriu que eu persistisse. Eu o fiz, e passei uma parte dos próximos quatros anos no mar, com a Marinha de guerra".

\section{ROLLS-ROYCE, ESCOLHA ESTRATÉGICA E POR QUE OS EXECUTIVOS SÃO IMPORTANTES}

John Child fez algo que poucos pesquisadores da administração fazem - trabalhar em período integral em uma corporação global. Os dois anos que Child passou na Rolls-Royce afetaram seu pensamento sobre o management de muitas maneiras. Essa influência foi talvez mais claramente demonstrada por sua formulação da perspectiva de escolha estratégica, descrevendo o "processo pelo qual top managers decidem buscar a mudança por meio de uma direção estratégica da organização". Child atribui muito de seu pensamento à tolerância do gerente de recursos humanos da Rolls-Royce Oil Engine Division, Barney Mathias, que lhe deu liberdade de aprender, experimentar e pesquisar questões relacionadas a gerenciamento e desenho organizacional.

No contexto de uma pesquisa dominada pela "teoria da contingência", muitos pesquisadores contemporâneos formularam conceitos de desenho organizacional que parecem primariamente determinados pelo meio ambiente enfrentado pela organização. Child notou, entretanto, que diferentes departamentos da Oil Engine Division da Rolls-Royce faziam suas próprias opções preferenciais para ter sucesso em suas respectivas tarefas ambientais. Considerando que todos os departamentos enfrentavam essencialmente o mesmo ambiente, não havia uma concordância sobre o desenho organizacional para um contexto ambiental uniforme. Baseado nessas observações, Child formulou sua perspectiva de escolha estratégica, sustentando que o ambiente organizacional não é um fator objetivo, mas algo que é constantemente reinterpretado e disputado pela equipe de top managers da organização. Os executivos não são dominados por ambientes determinísticos, mas fazem muitas escolhas estratégicas em relação ao desenho e aos sistemas técnicos, seja para crescer ou para fazer novos contratos, seja para permanecer ou gravitar em torno de uma tarefa ambiental menos dinâmica, e assim por diante.

A perspectiva da escolha estratégica dirige-se para uma das mais fundamentais considerações que confrontam a pesquisa e a prática da administração: se o ambiente organizacional determina sua estrutura e suas decisões críticas, os executivos importam muito pouco; mas, se os executivos não importam, a pesquisa de administração menos ainda. Por outro lado, se o estado do ambiente organizacional é discutível e sujeito à interpretação, os executivos fazem uma grande diferença, assim como nossas tentativas de entender os processos de tomadas de decisão estratégicas.

Tanto a teoria da contingência quanto o determinismo ambiental advogam ter desafiado grandemente a importância dos executivos na economia moderna. Alfred Chandler ilustra a importância dos assalariados, dos executivos de nível médio e dos top managers no desenvolvimento das empresas modernas e argumenta, convincentemente, que a "mão visível" do profissional do management vem substituindo a "mão invisível" da economia clássica na "coordenação dos fluxos e alocação de recursos". Nesse processo, de acordo com Chandler, as empresas têm se tornado uma fonte de "permanência, poder e crescimento continua- 
do". O determinismo ambiental desafiou a necessidade de uma mão visível, mas Child reforçou o papel das habilidades e do julgamento gerencial na formulação estratégica.

O trabalho de Child ensina-nos duas importantes lições sobre como fazer a pesquisa de administração importar para os executivos.

Primeiro, embora os executivos necessitem de justificativas práticas para permitir o acesso dos pesquisadores aos cenários organizacionais, desbloquear esse acesso pode resultar no que James March chamou, em uma perspectiva acadêmica, de "desenvolvimento de idéias fundamentais que moldam o pensamento gerencial". Primeiro-chairman do Citigroup e co-CEO, John Reed expressou uma visão similar, destacando que era essencial a ele se distanciar das pressões diárias dos negócios para obter acesso à pesquisa e à reflexão que aumentariam "o espaço de oportunidade" para o futuro do Citigroup.

Segundo, os pesquisadores devem entrar nas organizações com uma disposição de ir aonde as questões acontecem, ao invés de interpretar os fenômenos no contexto da sabedoria acadêmica convencional. Child foi capaz de ir além do contexto de pesquisa dominado pela teoria da contingência e, ao fazer isso, desenvolveu uma explicação para o comportamento observado, que era inconsistente com o pensamento corrente.

\section{THREE MILE ISLAND: PENSANDO 0 IMPENSÁVEL}

A crise do management, como um campo formal de pesquisa e prática, obteve recentemente "seu lugar." Centros de excelência têm sido estabelecidos em universidades líderes e os consultores vêm fazendo fortuna aconselhando as corporações a como sobreviver às crises e controlar o prejuízo associado. Desde 11 de setembro de 2001, os executivos gastam cada vez mais tempo pensando e planejando os perigos reais colocados pelas crises terroristas, assim como a crescente complexidade das tecnologias que são características de nossa sociedade industrial moderna. A base a partir da qual muitas decisões face à crise gerencial são tomadas, hoje, nas salas de diretoria pode ser traçada a partir dos resultados de uma pesquisa realizada em 1979 sobre o acidente ocorrido na usina de geração de energia nuclear de Three Mile Island, que foi baseada no pensamento de Charles Perrow e na publicação de seu livro Normal Accidents: Living with High Risk Technologies.

Perrow conta uma assustadora história sobre como ele tinha pedido a Cora Marrett, uma estudante e funcionária do governo, para estudar o acidente, fornecendo uma perspectiva sociológica para uma investigação predominantemente técnica e científica, e o efeito que isso teve nele, pessoal e profissionalmente. Quando ele revisou o material da investigação, declarou: "Examinei as transcrições naquela tarde e não podia dormir. Quando eu caí no sono, tive os piores pesadelos que já havia tido desde meus tempos de exército. O testemunho dos operadores causou uma impressão profunda sobre mim. Aqui estava um enorme e catastrófico risco tecnológico e eles não tinham idéia do que estava acontecendo por algumas horas... Subitamente, percebi que estava no meio disso, bem no meio disso, porque era um problema organizacional mais do que qualquer outra coisa, e que eu era um teórico organizacional".

Embora a atenção hoje esteja focada em impensáveis atos terroristas, o subtítulo do livro de Perrow, Living with High Risk Technologies, enfatiza o fato de que organizações altamente complexas e sistemas tecnológicos apresentam igualmente sérios perigos. Antes de sua imersão nos fatos de Three Mile Island, Perrow vinha formulando uma tese para um livro, provisoriamente intitulado A Society of Organizations. Ele notou que acidentes normais ou sistêmicos ocorreram em todas as organizações que ele tinha observado, inclusive nas corporações. Sua tese, mesmo antes de Three Mile Island, era a de que, quando os sistemas são pequenos e relativamente independentes, o resultado danoso pode ser contido. Quando os sistemas se tornam maiores e mais inter-relacionados, tornam-se crescentemente inadministráveis e falhas irreparáveis são mais prováveis de acontecer. Perrow tinha uma "teoria primitiva" sobre complexidade e interconexão. Three Mile Island ofereceu-lhe um caso com o qual ele pôde testar sua teoria. Há pouca dúvida de que as organizações de hoje e, em grande medida, as do futuro estão se tornando cada vez mais inter-relacionadas. Acidentes normais irão acontecer e os executivos terão de se tornar experts sobre como responder a isso de modo apropriado.

A oportunidade oferecida a Perrow por Marret para estudar os aspectos sociológicos da crise de Three Mile Island levou à outra pesquisa original sobre como "pensar o impensável" e, em última instância, como "administrar o inesperado". Essa pesquisa investigou tópicos que abrangem desde acidentes de avião aténatrasos no embarque de trens. As lições aprendidas com Three Mile Island, em 1979, não tiveram de 
esperar muito para serem testadas e refinadas por executivos que enfrentaram crises: a crise de 1980 da Procter \& Gamble com o tampão Rely, a crise da Johnson \& Johnson's com as cápsulas extrafortes do Tylenol, e o vazamento químico da Union Carbide Bhopal, Índia, que, em estimativas conservadoras, matou 2 mil pessoas e cegou mais umas 250 mil. Roberts e Bea, por exemplo, argumentam que o trabalho de Perrow tem sido útil para profissionais que estudam por que aviões caem, represas colapsam, navios colidem e fábricas explodem.

O trabalho de Perrow ensina-nos duas importantes lições sobre fazer pesquisa de administração que importa para os executivos.

Primeiro, que oportunidades são criadas quando os executivos reconhecem que precisam pensar de forma "fora do padrão" sobre problemas convencionais. Para muitas pessoas, Three Mile Island foi um problema de engenharia, mas Marret reconheceu o potencial benefício de se valer de uma perspectiva sociológica para enriquecer e esclarecer uma perspectiva exclusivamente técnica.

Segundo, os pesquisadores podem criar direções novas e produtivas no desenvolvimento do conhecimento por meio do pensamento, que vai além de seus modelos convencionais de pesquisa. Embora inicialmente cético, Perrow veio a apreciar o caso Three Mile Island como um problema organizacional e começou a trabalhar aplicando seu conhecimento como teórico das organizações. Ele havia tido uma carreira confortável e notável na sociologia organizacional tradicional. Sua pesquisa sobre Three Mile Island, entretanto, não somente resultou em uma prática relevante para o conhecimento, como também influenciou a direção de seu trabalho nos anos seguintes.

\section{RAND, LOCKHEED E ESTRATÉGIA CORPORATIVA MODERNA}

Os pesquisadores algumas vezes recorrem às suas experiências organizacionais pessoais, em um lugar particular, para definir e refinar suas idéias. A curiosidade sobre por que as organizações operam da maneira como o fazem é uma valiosa fonte de questões e hipóteses de pesquisa, como foi ilustrado no caso de Child na Rolls-Royce. As experiências de Igor Ansoff, na Rand Corporation, enquanto administrava um grande projeto na avaliação da vulnerabilidade das forças áreas da Otan ao ataque soviético, também fornecem uma plataforma única para seu futuro pensamento sobre as organizações.

De acordo com Ansoff, um modelo que ele desenvolveu em seu trabalho na Otan incluía um número de variáveis não técnicas que eram incomuns nos estudos da Rand. Na Rand, o costume era apresentar estudos para a crítica e avaliação do staff interno antes de serem repassadas para os clientes. Ansoff observou que, na visão do staff da Rand, a introdução de variáveis "soft", que tornariam as predições de seu modelo mais realistas e importantes, seria uma deficiência. Escrevendo sua autobiografia, ele percebeu que esse era seu primeiro encontro com a miopia organizacional. Em uma experiência relacionada, envolvendo um estudo do Strategic Air Command (SAC), Ansoff observou: "Embora eu não tenha percebido naquela época, a rejeição pelo SAC e a quase rejeição pelo staff da Rand continham insights valiosos sobre o modo como as organizações reagem aos estudos que contradizem seu comportamento e suas experiências históricas. Esses insights emergiram de meu subconsciente 20 anos mais tarde e ajudaram-me a entender e lidar com os problemas de resistência gerencial às mudanças estratégicas descontínuas".

Mais pertinente para nossos propósitos foi a decisão de Ansoff de se tornar membro do Corporate Planning Department da Lockheed Aircraft Corporation. Robert Gross, o CEO da Lockheed, colocou Ansoff como responsável pela diversificação da força-tarefa. Em conseqüência, Ansoff ampliou o foco de sua atenção em relação ao desafio de administrar organizações que enfrentam descontinuidades ambientais, as quais se tornaram o tema central de seu trabalho por três décadas.

Todos esses incidentes indicam a influência que Rand, Lockheed e Mr. Gross tiveram sobre o indivíduo que se tornou conhecido como "o pai da administração estratégica". Ansoff foi o principal contribuidor para o entendimento que os executivos contemporâneos têm sobre o processo decisório estratégico, e grande parte de seu clássico livro Corporate Strategy: An Analytic Approach to Business Policy for Growth and Expansion, foi baseada em sua experiência como executivo.

O trabalho de Ansoff ensina-nos duas importantes lições sobre como fazer pesquisa de administração que importa para os executivos.

Primeiro, as práticas organizacionais e os executivos que as desenvolvem freqüentemente envolvem mais do que uma simples pesquisa aplicada. Na realidade, muito da pesquisa de administração é baseado na observação de práticas organizacionais. A experiên- 
cia de Ansoff demonstra que uma mente aberta e perceptiva provavelmente encontrará ricas possibilidades de pesquisa relacionadas às realidades organizacionais rotineiras.

Segundo, a pesquisa baseada na observação participativa em cenários organizacionais pode requerer métodos de pesquisa inovadores para capturar a riqueza da realidade organizacional sem sacrificar a validade interna necessária à generalização dos resultados. Em conseqüência, pode ser desafiante aceitar métodos não ortodoxos, assim como usar a pesquisa gerada dessa forma para informar a prática gerencial.

\section{CONHECIMENTO ESPIRAL: REQUISITOS PARA ENCONTROS CONSCIENTES}

Esses quatro casos oferecem lições particulares em relação à pesquisa de administração que importa para os executivos. Claramente, a pesquisa de administração pode ser, e tem sido, útil para os executivos práticos. Alguns livros, tais como Built to Last, escrito por pesquisadores acadêmicos, são largamente lidos por executivos. Entretanto, tais livros, assim como os casos que discutimos, são mais exceções do que regra. Por que ficamos impressionados pos encontros bem-sucedidos entre pesquisadores e executivos ou quando um livro de um pesquisador acadêmico integra a lista de best-sellers? Não deveríamos imaginar que muitas, talvez a maioria, das práticas convencionais do management emergiram de parcerias mutuamente benéficas para executivos e pesquisadores? O que seria necessário para encorajar a geração de novos conhecimentos científicos sobre organizações e gerenciamento e, ao mesmo tempo, para produzir pesquisas que podem ser utilizadas por aqueles que são responsáveis pelo cotidiano organizacional?

As lições aprendidas nos casos previamente discutidos contam-nos muito sobre quais necessidades podem ser atendidas para encorajar mais pesquisas relevantes à pesquisa de administração. Tais pesquisas requerem que os executivos, os pesquisadores e as organizações tenham certas qualidades. Os encontros descritos em cada caso ocorreram entre executivos experientes que apoiaram e confiaram nos pesquisadores e não foram avessos aos riscos profissionais e, algumas vezes, pessoais. Os executivos estavam dispostos a patrocinar novas formas de entendimento de suas organizações e tiveram confiança suficiente em si mesmos para solicitar e encorajar novas pers- pectivas. Os pesquisadores estavam dispostos a entrar em ambientes pouco familiares, até mesmo desconfortáveis, e a se mover para além dos limites das teorias existentes para perceber realidades organizacionais fora das fronteiras estabelecidas pelas descrições convencionais. Essas são importantes lições, mas os insights obtidos são insuficientes para nos oferecer meios de aumentar a probabilidade de parcerias mutuamente benéficas entre executivos e pesquisadores. Felizmente, existem pesquisas que provêem uma base para tal entendimento.

Nonaka e Takeuchi introduziram a noção de "espiral de conhecimento" para descrever como estimular intercâmbios úteis que podem ocorrer entre executivos e pesquisadores. Um espiral de conhecimento começa quando executivos e pesquisadores socializam ou se associam por meio de contratos de consultoria, reuniões profissionais e programas de executivos in company. Executivos e pesquisadores tornam-se mutuamente conscientes sobre suas pressuposições, percepções e valores, e, conseqüentemente, alcançam um entendimento mais profundo das perspectivas de cada um. Isso torna então possível que executivos e pesquisadores partilhem do conhecimento explícito necessário para os projetos de pesquisa e cooperem como membros de equipes de pesquisa. Finalmente, o objetivo mais importante é atingido quando a pesquisa é usada para informar e influenciar as práticas gerenciais.

\section{INTERAÇÃO: A NECESSIDADE DO PRIMEIRO PASSO}

Embora a interação entre executivos e pesquisadores não assegure colaboração, as parcerias não podem se desenvolver sem intercâmbios face-a-face. Quando executivos e pesquisadores se juntam com o propósito de verdadeiramente aprender uns com os outros, um "círculo virtuoso" começa a se formar. O círculo não irá, entretanto, formar-se facilmente. Diferenças e incompatibilidades importantes nos estilos de resolução de problemas devem ser resolvidas.

No estudo conduzido por Dossabhoy e Berger sobre os pesquisadores das business schools, reitores, egressos dos MBAs executivos e executivos seniores, foi feita uma tentativa de determinar o que cada grupo pensa como sendo as características de uma pesquisa exemplar em administração. As características identificadas pelos pesquisadores foram similares às 
reconhecidas pelos reitores, assim como as características identificadas pelos MBAs foram similares às reconhecidas pelos executivos seniores. Já as características identificadas pelos pesquisadores e reitores diferiram significativamente das características identificadas pelos MBAs e executivos seniores.

O "modelo executivo" (MBAs executivos e executivos seniores) via a pesquisa exemplar começando com uma explicação da realidade gerencial, escrita em termos breves e concisos e com implicações diretas na ação gerencial. As implicações deveriam levar a recomendações explícitas que ajudassem na solução de problemas gerenciais reais. A pesquisa de administração, nesse modelo, deveria melhorar a performance corporativa e ser útil para o andamento dos negócios

A cultura e o ambiente competitivo das empresas requerem que os executivos tomem decisões rápidas e freqüentemente com insuficiência de informações. O modelo executivo é considerado essencial no acelerado mundo dos negócios, mas pode ocasionar processos decisórios "rápidos e às vezes sujos", o que é estranho ao cauteloso e cuidadoso pesquisador Os pesquisadores são treinados para buscar informações, mesmo sob o risco e o custo de gastar mais tempo. No ambiente acadêmico, a informação é vista mais como um ativo do que como um custo. A pesquisa de qualidade preocupa-se com questões de gerenciamento e organização que são "maiores" do que as soluções para problemas imediatos e é focada nas "idéias básicas que moldam o discurso sobre o management". A interação de executivos e pesquisadores pode levar a uma compreensão, senão a uma apreciação, das perspectivas de diferentes comunidades profissionais.

\section{EXPANDINDO PERSPECTIVAS}

A pesquisa de Dossabhoy e Berger confirmou que quanto maior o grau de aceitação de perspectivas entre os executivos e os pesquisadores, maior será o uso da pesquisa para informar a prática gerencial. A aceitação de perspectivas, no entanto, não é resultado automático da interação. Perceber a utilidade da pesquisa requer mais do que unir tópicos definidos para serem pesquisados. Envolve um relacionamento entre os executivos e os pesquisadores. Tem sido dito que "ser acadêmico demais e ser insuficientemente acadêmico inevitavelmente gera uma imaginação persecutória". Imaginações persecutórias são disfuncionais. A verdadeira aceitação de perspectivas, entretanto, pode re- duzir muitos efeitos negativos que afetam pesquisadores e executivos.

Um excelente exemplo da importância da interação com vistas à aceitação de perspectivas é estabelecido por Roberts. Quando ela e seus colegas começaram sua pesquisa nas HROs, uma das primeiras atitudes foi reconciliar "oficiais da Marinha e executivos do sistema de controle de tráfico aéreo da FAA, na área da baía, e o pessoal da usina nuclear, em Diablo Canyon. A embarcação proporcionou um dia de workshop para que os executivos dessas unidades pudessem conversar sobre seus desafios comuns".

A aceitação de perspectivas deve começar com o reconhecimento de que nem todos os pesquisadores devem tentar realizar pesquisa relevante para a prática e de que nem todas as organizações devem patrociná-la. Nesse aspecto, há dois modelos de conhecimento de administração. Cada tipo advém de uma subcultura de pesquisa relativamente bem definida, mas isolada. O modelo 1 de conhecimento (M1K) é científico no senso convencional que interessa às universidades; é disciplinar; é e mais focado na teoria do que na prática. O M1K deriva da adesão ao modelo acadêmico tradicional. Esse modelo, aprovado pelos pesquisadores acadêmicos, defende que a pesquisa deveria começar com questões relevantes e ser concluída com contribuições para o conhecimento teórico. A pesquisa deve ser baseada em premissas sensatas, a partir das quais as hipóteses podem ser desenvolvidas e testadas. A pesquisa acadêmica requer amostragem apropriada e análise rigorosa de dados por meio da qual inferências lógicas podem ser feitas. Os resultados precisam ser internamente consistentes e propor generalizações defensáveis, que podem ser reproduzidas por outros pesquisadores.

O modo de conhecimento 2 (M2K) é rigoroso, mas transdisciplinar, estando mais voltado para o conhecimento utilizado na aplicação prática. Esse tipo de conhecimento tem como objetivo gerar insights sobre um contexto particular com vistas a obter soluções práticas para identificar problemas gerenciais. Os usuários do M2K necessitam de sofisticação e rigor metodológico o suficiente para garantir que a evidência que baseia suas decisões seja sensata.

Em geral, os pesquisadores universitários têm interesse em gerar conhecimento do tipo M1K e se resguardam na busca e disseminação de conhecimento em favor do próprio conhecimento. Em contraste, as empresas tipicamente têm pouco interesse em patrocinar pesquisas que podem resultar em tornar pública 
uma vantagem competitiva. Compreensivelmente, como os pesquisadores acadêmicos estão comprometidos no desenvolvimento do M1K, não se deve esperar que eles gerem M2K, e como os executivos estão interessados no uso do conhecimento como ferramenta competitiva, não se deve esperar que eles disponibilizem gratuitamente resultados de pesquisa do tipo M2K.

Quando os executivos, entretanto, debatem internamente questões gerenciais, e o debate pode ser relacionado a agendas mais universais de pesquisa, a aceitação de perspectivas de todas as partes tem o potencial de facilitar a construção de redes efetivas de colaboração para o desenvolvimento do conhecimento. Idealmente, a disseminação de resultados relevantes nessas redes deveria ocorrer como parte integrante do processo de pesquisa.

Parcerias entre executivos e pesquisadores ou redes oferecem a promessa de fazer a pesquisa de administração mais útil para os executivos por meio do aumento de sua qualidade e relevância. Geralmente se reconhece que os executivos tomam decisões operacionais baseados em seu entendimento da história de uma empresa, seu background e as experiências passadas nas quais estiveram envolvidos. No desenho de seus estudos, os pesquisadores procedem da mesma maneira. Como Neustadt e May observaram, o contexto requer que tanto os executivos quanto os pesquisadores pensem "em tempo real". Considerando que fazer isso ajuda os pesquisadores na identificação de questões de pesquisa de alto valor agregado, isso também ajuda os executivos a investigarem como as recomendações operacionais poderiam ser afetadas pelas mudanças nas condições e pressuposições da indústria.

\section{UM VISLUMBRE DE ESPERANÇA}

Embora a pesquisa de Dossabhoy e Berger confirme que, de fato, há um gap entre as características da pesquisa exemplar de administração, e, como ela é percebida pelos acadêmicos e executivos, existe uma área de concordância que poderia proporcionar um ponto de partida para transcender esse gap, além de induzir mais exemplos de parcerias mutuamente benéficas entre executivos e pesquisadores. Dossabhoy e Berger descobriram que há características da pesquisa exemplar de administração que acadêmicos e executivos concordam serem importantes. Ambos admitem que a pesquisa exemplar de administração deveria emergir de problemas críticos, ter um claro propósito, ser coerentemente escrita, usar fontes de dados confiáveis, ser objetiva e imparcial, estabelecer uma estrutura conceitual, ser original e inovadora, generalizável para além do próprio contexto, desafiar suposições correntes, ter recomendações sustentadas por dados, proporcionar muitas boas idéias e ser baseada em premissas válidas.

Dossabhoy e Berger também sugerem um modelo para superar o gap: uma transcendência em vez de uma mera integração dos modelos acadêmico e executivo. A pesquisa exemplar de administração conduzida sob esse modelo deveria transcender os objetivos triviais que tanto os acadêmicos quanto os executivos atribuem às questões críticas do management, ser claramente apresentada, resultar em recomendações para a ação baseadas em dados e análise válidos e ser sujeita à verificação. Essa pesquisa deveria atender às necessidades das mais exigentes comunidades acadêmicas e assegurar uma base de controle de qualidade. Ela deveria, também, adicionar valor real ao processo decisório gerencial. As recomendações deveriam ser baseadas em dados, ao invés de especulações, e estabelecer diretrizes para a ação gerencial.

Uma pesquisa de administração que fosse crítica, verificável, válida, útil e clara não apenas tornaria a pesquisa acadêmica mais útil, mas também melhoria sua qualidade. Os executivos, por sua vez, oprimidos com problemas e soluções especulativas, iriam dar boasvindas à pesquisa gerada de acordo com um modelo de transcendência, teriam mais confiança em relação à sua utilidade e se tornariam consumidores mais seletivos da pesquisa de administração.

\section{UMA AGENDA DE AÇÃo}

Nosso exame da gênese de pesquisa relevante para a prática e sua transferência para a prática gerencial sugere uma agenda para aumentar a probabilidade de geração de pesquisa com essas características. Existem, na verdade, alguns passos específicos que os pesquisadores universitários e os executivos podem e devem seguir para encorajar mais e melhores pesquisas relevantes para a prática gerencial. Ocasionalmente, como os quatro casos indicaram, o M2K desenvolvese como resultado de acidentes ou coincidências incomuns. O valor potencial de tal informação encoraja-nos a oferecer a seguinte agenda para aumentar a 
probabilidade de que a pesquisa de administração seja usada para incrementar a prática executiva:

1. Tanto pesquisadores universitários quanto executivos devem procurar ativamente oportunidades de desenvolver fóruns de interpretação conjunta, envolvendo executivos e pesquisadores de administração. Tais fóruns encorajariam a socialização e poderiam ter a forma de simpósios co-patrocinados nas reuniões profissionais, nos programas de executivos in company e outros. Os fóruns de interpretação conjunta são úteis para engajar executivos e pesquisadores na definição de questões, reflexão e interpretação de informação e sugestão de esforços de definição de desenho organizacional usando resultados de pesquisas. O patrocínio da Marinha dos Estados Unidos para convocar um workshop sobre redução de riscos, por exemplo, foi fundamental para envolver os executivos e influenciar o direcionamento inicial da pesquisa de Roberts.

2. Os fóruns de interpretação conjunta deveriam ser encorajados e patrocinados por sociedades profissionais, empresas e universidades, pois as evidências sugerem claramente que a interação mais freqüente entre executivos e pesquisadores ocasiona um aprofundamento das relações e encoraja a aceitação de perspectivas entre eles. Apenas realizar pesquisas sobre temas relevantes para os executivos não gera a aceitação de perspectivas. Esta ocorre quando os pesquisadores entendem o que um tema significa para os executivos e os executivos compreendem como os pesquisadores percebem diferentes questões.

3. Enquanto protegem a pesquisa M1K, as universidades deveriam também encorajar ativamente, e recompensar, a pesquisa M2K que, por intermédio das informações relevantes para a prática, resulta no engajamento das organizações na melhoria de seu próprio desenho e de suas próprias atividades.

4. A importância da perspectiva crítica, da verificabilidade, da validade, da utilidade e da clareza deve ser enfatizada no treinamento dos pesquisadores de administração junto às habilidades convencionais associadas à pesquisa acadêmica. Esforços devem ser realizados para demonstrar tais qualidades em toda pesquisa de administração, na esperança de que os executivos comecem a perceber que a pesquisa tem o potencial de ser compreendida, de melhorar a performance organizacional e de agregar valor genuíno.

5. Os pesquisadores devem se comprometer com acompanhamentos de longo prazo e avaliações das aplica- ções da pesquisa de administração para determinar a extensão na qual ela é realmente útil para a prática gerencial. Raramente algum resultado científico é perfeito em sua primeira aplicação. A prática gerencial partilha com a descoberta científica uma importante característica: ambas melhoram com aplicação, testagem e refinamento. As universidades, da mesma maneira, deveriam se tornar mais tolerantes com a pesquisa que envolve mais tempo e superar a tendência de julgar a produtividade acadêmica pelo número de publicações, ao invés de medir a significância de seu impacto na comunidade acadêmica.

6. As universidades deveriam reconhecer a importância da pesquisa que é crítica, verificável, válida, útil e clara, mesmo que não seja publicada nas mais prestigiadas revistas da área. Essas revistas, por sua vez, também deveriam se tornar mais receptivas à pesquisa que segue o modelo de transcendência, tanto quanto o modelo acadêmico tradicional. A tolerância também deveria ser aplicada a livros escritos primariamente para executivos e publicados por editoras mais orientadas ao mercado. Talvez as editoras universitárias pudessem se tornar importantes atores na publicação de trabalhos que transcendessem o público acadêmico. Tal nicho poderia encontrar parceiros dispostos nas corporações e outras organizações que poderiam ver esses investimentos como alternativas de valor agregado aos exorbitantes honorários de consultorias.

7. As empresas e outras organizações deveriam buscar oportunidades de parcerias com pesquisadores universitários para investigar questões que estão abertas ao debate, mas somente quando houver um claro entendimento de que os resultados das pesquisas serão livremente disseminados para um público mais amplo.

8. As parcerias produtivas entre executivos e pesquisadores podem ser valiosas para todos os interessados, mas aumentar a probabilidade de encontros conscientes deve ser um processo deliberado. Esses encontros, quer sejam acidentais ou conscientes, devem ser ativamente encorajados. Entretanto, há um paradoxo. Parcerias produtivas não irão se desenvolver até que executivos, pesquisadores, universidades e organizações reflitam sobre os próprios termos não convencionais aos quais as parcerias visam a encorajar. No clássico "beco sem saída", entretanto, não podemos pensar de um modo não convencional sobre nossas suposições, papéis e valores até que desenvolvamos, primeiro, parcerias efetivas. Nada, exceto uma "reengenharia" das relações entre executivos e pesquisadores, é necessário. 


\section{UMA SUGESTÃO FINAL}

Ninguém sugeriria que mesmo o mais arrogante e míope dos executivos ou pesquisadores não está interessado em meios de facilitar a tradução do pensamento gerencial em prática gerencial. De maneira defensável, muitas pessoas, ao menos intelectualmente, vêem a necessidade de parcerias mutuamente benéficas entre executivos e pesquisadores. De fato, pesquisadores da administração freqüentemente seguem certas convenções para sugerir como executivos deveriam fazer seu trabalho. Por exemplo, uma seçãopadrão na maioria dos artigos de pesquisa de administração é a "So What". Habitualmente, tal seção vem no final dos artigos e esboça indicações de como a pesquisa relatada poderia ser utilizada para melhorar a prática gerencial. Esse é um passo positivo, tendo em vista a aceitação de perspectivas. Infelizmente, é uma abordagem unilateral. As suposições presentes na seção "So What" das revistas são numerosas e, muitas vezes, errôneas.

Por exemplo, para que essa seção seja valiosa, os executivos primeiro deveriam ler o artigo em que ela se encontra. Em muitos casos, o objetivo do artigo é relatar uma pesquisa M1K e os executivos tipicamente não lêem as revistas nas quais esse tipo de pesquisa é publicada. Uma suposição igualmente questionável é que os pesquisadores M1K são capazes de reconhecer o que seu trabalho significa para os executivos. $\mathrm{Na}$ ausência de uma aceitação de perspectivas, que só vem de uma interação conjunta, há uma alta probabilidade de que tanto os executivos quanto os pesquisadores simplesmente percam de vista "o ponto". Em outras palavras, a seção "So What" nos artigos que relatam pesquisa M1K dificilmente adiciona algo para o entendimento dos pesquisadores sobre as implicações do trabalho ou para o entendimento dos executivos de como eles poderiam utilizar a pesquisa relatada para melhorar a prática. Nos artigos que relatam pesquisa $\mathrm{M} 2 \mathrm{~K}$, as implicações deveriam ser evidentes, e a seção "So What", desnecessária.

Talvez uma seção mais importante devesse ser colocada no início dos artigos, e ser intitulada "Por que esta pesquisa deveria importar para os executivos". Essa seção conteria um breve background de como as idéias que sustentam a pesquisa foram desenvolvidas e poderia conter aplicações introdutórias, tais como aquelas de Carney e a Sears, Child e a Rolls-Royce ou Roberts e a USS Carl Vinson, entre outras. Isso poderia "prender" o interesse dos executivos e mesmo su- gerir questões mais amplas para os que estão focados exclusivamente nos desafios cotidianos. A meta seria fornecer, de início, uma verificação de que a questão examinada é potencialmente importante para os executivos. Admitimos, no entanto, que essa também é uma visão unilateral, que favorece os executivos ao conduzir a pesquisa de administração.

\section{DESAFIOS FUTUROS}

Neste artigo, chamamos por parcerias entre executivos e pesquisadores baseadas em uma aceitação de perspectivas que assegure que eles realmente entendam e respeitem as suposições, os valores e métodos de cada um. Sugerimos que a probabilidade dos executivos e pesquisadores de se envolverem em todos os estágios da pesquisa gerencial aumentará graças a atividades como os fóruns de interpretação conjunta, patrocinados por sociedades profissionais, empresas e universidades.

Também apontamos os benefícios que podem ser adquiridos pelos executivos e pesquisadores na formação de parcerias significativas, e ainda argumentamos que as parcerias trabalham melhor quando as diferentes partes desempenham os papéis apropriados. Baseados nas considerações realizadas, desafiamos executivos e pesquisadores a pensarem sobre esses papéis e a trabalharem para aperfeiçoá-los, assim como a maximizarem a sinergia que pode ser obtida das experiências conjuntas, que efetivamente facilitem a aceitação de perspectivas.

Também desafiamos os executivos a catalogarem os desafios recorrentes que enfrentam administrando suas organizações e a documentarem, na medida do possível, o porquê dos desafios se manterem. Quando estes estiverem catalogados, os executivos serão encorajados a discutir os desafios com os pesquisadores, a oferecer acesso a suas organizações, a interferir no trabalho dos pesquisadores, a questionar seus resultados e a envolver os pesquisadores na implementação de novas práticas. Dessa forma, questões reais podem ser equacionadas e o processo decisório baseado em dados pode ser aplicado nos futuros desafios.

Pedimos para que os pesquisadores sejam receptivos aos executivos que desejam tomar decisões informados pela pesquisa. Os pesquisadores precisam ver esses convites como oportunidades de investigação, em vez de oportunidades de consultoria. A aceitação de perspectivas é realizada quando desafios reais são iden- 
tificados e quando uma pesquisa coerente é aplicada na solução desses desafios. Abordar tais tarefas a partir da perspectiva da consultoria cria conflitos de interesse, lança suspeitas sobre os resultados e limita as oportunidades de acesso. Além disso, a consultoria é uma core competence das firmas de consultoria e não dos pesquisadores universitários. Pedimos para que as universidades resguardem a pesquisa M1K, mas também valorizem e encorajem apropriadamente a pesquisa M2K. Antes de serem consideradas menos prioritárias porque são aplicadas, espera-se que os professores universitários vejam essas pesquisas como sendo valiosas por informarem e melhorarem a prática gerencial. Finalmente, demandamos um sério reconhecimento do modelo transcendente para a pesquisa exemplar de administração, baseada nos critérios da abordagem crítica, da verificabilidade, da validade, da utilidade e da clareza. Esses critérios proporcionam uma estrutura para novas e estimulantes abordagens de pesquisa, que evitam a irrelevância do modelo acadêmico e a obsessão pela prática do modelo executivo.

Imaginemos quantas pesquisas importantes nunca teriam acontecido, e quantas melhorias na prática gerencial teriam sido perdidas, se não tivesse havido o encorajamento de executivos como Barney Mathias da Rolls-Royce, as questões e direcionamentos de C. T. Carney e Roebuck na Sears e de Robert Gross na Lockheed, o apoio de Admiral Thomas Mercer e as previsões de Cora Marret, que queria entender as razões humanas por trás do desastre de Three Mile Island. Talvez mais importantes sejam a quantidade e a qualidade das pesquisas e práticas de administração que poderíamos esperar no futuro por meio do encorajamento de parcerias mutuamente benéficas, construídas com uma efetiva aceitação de perspectivas entre executivos e pesquisadores.

Se escolhermos ser pessimistas e concluirmos que as listas de best-sellers refletem de forma acurada a influência relativa que pesquisadores acadêmicos, jornalistas e consultorias têm no processo decisório, devemos então perguntar: "Nossa contribuição é pequena por que somos irrelevantes?" ou "Somos irrelevantes por que contribuímos tão pouco?". Qualquer que seja a resposta, a situação não é desesperançosa. Devemos, primeiro, nos tornar menos viciosos e mais comprometidos a produzir, encorajar e recompensar a pesquisa que é transcendente em sua essência e então desenvolver e nutrir parcerias mutuamente benéficas entre executivos e pesquisadores. A pesquisa de administração deve dar o primeiro passo. As empresas pro- varam que elas podem sobreviver e serem bem-sucedidas sem depender da pesquisa acadêmica. Os pesquisadores devem demonstrar como eles podem adicionar valor, oferecendo idéias que melhorem a performance organizacional.

Texto traduzido por Ana Paula Paes de Paula.

Artigo convidado. Aprovado em 01.06.2003.

\section{Notas}

Os autores desejam expressar sua gratidão a F. Wayen Pate, B. S., antigo presidente da Golden Enterprises; Fay Boozman, M. D., M. P. H., diretor da Arkansas Department of Health, e Andrew C. Rucks, Ph. D., consultor gerencial, pela leitura dos primeiros rascunhos deste artigo e a oferta de sugestões para tornar a discussão relevante aos executivos.

Artigo originalmente publicado na Academy of Management Executive, v. 17, n. 1, p. 46-60, fevereiro 2003

Copyright 2003 Academy of Management. Todos os direitos são reservados. Nenhuma parte deste artigo pode ser reproduzida por qualquer meio ou forma sem a permissão por escrito da Academy of Management. Para obter autorização, entre em contato com Copyright Clearence Center: www:copyright.com.

\section{Referências bibliográficas}

ABRAHAMSON, E. e FAIRCHILD, G. Management fashion: lifecycles, triggers, and collective learning processes. Administrative Science Quarterly, v. 44, n. 4 , p. $708-40,1999$.

ABRAHAMSON, E. Management fashion. Academy of Management Review, v. 21, n. 1, p. 257, 1996.

ABRAHAMSON, E. Managerial fads and fashions: the diffusion and rejection of innovations. Academy of Management Review, v. 16, n. 3, p. 586-612, 1991.

AMABILE, T. M. et al. Academic-practitioner collaboration in management research: a case of cross-profession collaboration. Academy of Management Journal, v. 44, n. 2, p. 418-31, 2001

ANDERSON, S. J., COHEN e TAYLOR, S. Rewriting the past: some factors affecting the variability of personal memories. Applied Cognitive Psychology, v. 14, n. 5 , p. $435-54,2000$.

ANSOFF, H. I. A profile of intellectual growth. In: BEDEIAN, A. G. Management laureates: a collection of autobiographical essays. Greenwich : JAI Press. v. 1, 1992.

BEDEIAN, A. G. Management laureates: a collection of autobiographical essays. Greenwich : JAI Press. v. 1, 1992 ; v. 2, 1993a; v. 3, 1993b; v. 4 , 1996; v.5, 1998 e v.6, 2002. 
BOHL, D. L. et al. Ideas that will shape the future of management practice. Organizational Dynamics, v. 25, n. 1, p. 6-13, 1996.

CARSON, P. P., LANIER, P. A., CARSON, K. D. e GUIDRY, B. N. Clearing a path through the management fashion jungle: some preliminary trailblazing. Academy of Management Journal, v. 43, n. 6, p. 1143-58, 2000

CHANDLER JR., A. D. The visible hand: the managerial revolution in American business. Cambridge : Belknap Press of Harvard University Press, 1977.

CHANDLER JR., A. D. History and management practice and thought. In: BEDEIAN, A. G. Management laureates: a collection of autobiographical essays. Greenwich : JAI Press. v. 1, 1992, p. 215-7.

CHILD, J. Organizational structure, environment, and performance - The role of strategic choice. Sociology, v. 6, n. 1, p. 1-22, 1972.

CHILD, J. Mix context and choice, and add a large dose of serendipity. In: BEDEIAN, A. G. Management laureates: a collection of autobiographical essays. Greenwich : JAI Press. v.6, 2002, p.15.

COLLINS, J.C. e PORRAS, J. I. Built to last. New York : Oxford University Press.

DOSSABHOY, N. S. e BERGER, P. D. Business school research: bridging the gap between producers and consumers. Omega, v. 30, n. 4, p. 301-14, 2002

FINK, S. Crisis management: planning for the inevitable. New York : American Management Association, 1986.

GREY, C. Re-imaging relevance: a response to Starkey and Madan. British Journal of Management, v. 12, Special Issue, p. S27-32, 2001.

HAMBRICK, D. C. What if the Academy actually mattered? Academy of Management Review, v. 19, n. 1, p. 11-6, 1993.

HARLEY, K. e REESE, E. Origins of autobiographical memory. Developmental Psychology, v. 35, n. 5, p. 1338-48, 1999.

HATCHUEL, A. The two pillars of new management research. British Journal of Management, v. 12, Special Issue, p. S33-9, 2001

HITT, M. A., KEATS, B. W. e DEMARIE, S. M. Navigating the new competitive landscape: building strategic flexibility and competitive advantage in the $21^{\text {st }}$. century. The Academy of Management Executive, v. 12, n. 4, p. $28,1998$.

HODGKINSON, G. P., HERRIOT, P. e ANDERSON, N. Re-aligning the stakeholders in management research: lessons from industrial, work, and organizational psychology. British Journal of Management, v. 12, Special Issue, p. S45, 2001

HUFF, A. S. (Ed.). Citigroup's John Reed and Stanford's James March on management research and practice. The Academy of Management Executive, v. 14, n. 1, p. $52-64,2000$.

HUFF, A. S. e HUFF, O. Refocusing the business school agenda. British Journal of Management, v. 12, n. Special Issue, p. S50, 2001.
KELEMEN, M. e BANSAL, P. The conventions of management research and their relevance to management theory and practice. British Journal of Management, v. 13, n. 2, p. 97-108, 2002.

MACKAVEY, W. R., MALLEY, J. E. e STEWART, A. J. Remembering autobiographically consequential experiences: content analysis of psychologists' accounts of their lives. Psychologyand Aging, v. 6, n. 1, p. 509, 1991.

MATHER, M., SHERIF, E. e JOHNSON, M. K. Misremembrance of options past: source monitoring and choice. Psychological Science, v. 11, n. 2, p. $132-8,2000$

MERTON, R. K. Some thoughts on the concept of socio-logical autobiography. In: RILEY, M. W. E. (Ed.). Sociological lives. Newbury Park : Sage, 1988. p. 17-21.

MICKLETHWAIT, J. e WOOLDRIGE, A. The witch doctors: making sense of the management gurus. New York: Times Business, 1996.

MOHRMAN, S. A., GIBSON, C. B. e MOHRMAN, A. M. Doing research that is useful to practice: a model and empirical exploration. Academy of Management Journal, v. 44, n. 2, p. 357-75, 2001

NEUSTADT, R. E. e MAY, E. R. Thinking in time: the uses of history for decision makers. New York : Free Press, 1986.

NONAKA, I. e TAKEUCHI, H. The knowledge creating company. New York : Oxford University Press, 1995.

PERROW, C. Normal accidents: living with high risk technologies. New York : Basic Books, 1984.

PERROW, C. An almost random career. In: BEDEIAN, A. G. Management laureates: a collection of autobiographical essays. Greenwich : JAI Press. v. 3, 1993b, p. 429-30.

PERSONAL histories: leaders remember the moments and people that shaped them. Harvard Business Review, v. 79, n. 6, p. 27-38, 2001.

PFEFFER, J. e FONG, C. T. The end of business schools? Less success than meets the eye. Academy of Management Learning \& Education, v. $1, \mathrm{n}$. 1, p. 78-95, 2002.

PYENSON, L. Who the guys were: prosopography in the history of science. History of Science, v. 15, n. 2, p. 155-88, 1977.

ROBERTS, K. H. Having the bubble. In: BEDEIAN, A. G. Management laureates: a collection of autobiographical essays. Greenwich : JAI Press. v.5, 1998, p. 227.

ROBERTS K. H. e BEA, R. Must accidents happen? Lessons from high reliability organizations. The Academy of Management Executive, v. 15, n. 3 , p. $70-9,2001$.

ROSS, M., BUEHLER, R. e KERR, J. W. Assessing accuracy of conflicting autobiographical memories. Memory \& Cognition, v. 26, n. 6, p. 1233-44, 1998.

RYNES, S. L., BARTUNEK, J. M. e DAFT, R. L. Across the great divide: knowledge creation and transfer between practitioners and academics. Academy of Management Journal, v. 44, n. 2, p. 340-55, 2001. 
SHAPIN, S. e THACKRAY, A. Prosopography as a research tool in history of science: the British scientific community 1700-1900. History of Science, v. 12, n. 1, p. 1-28, 1974.

SHUM, M. S. The role of temporal landmarks in autobiographical memory processes. Psychological Bulletin, v. 124, n. 2, p. 423-42, 1998.

SPELL, C. S. Management fashions: where do they come from, and are they old wine in new bottles? Journal of Management Inquiry, v. 10, n. 4, p. 358-73, 2001

STARKEY, K. e MADAN, P. Bridging the relevance gap: aligning stakeholders in the future of management research. British Journal of Management, v. 12, Special Issue, p. S11, 2001.

STAW, B. M. e EPSTEIN, L. D. What bandwagons bring: effects of popular management techniques on corporate performance, reputation, and CEO pay. Administrative Science Quarterly, v. 45, n. 3, p. 523-56, 2000.

URWICK, L. F. e BRECH, E. F. L. The making of scientific management. 3 v. London : Management Publications Trust, 1947-1949.
URWICK, L. F. The golden book of management. London : Newman Neame, 1956.

WEICK, K. E. e SUTCLIFFE, K. M. Managing the unexpected: assuring high performance in an age of complexity. San Francisco : Jossey-Bass /Wiley Company 3, 2001.

WITZEL, M. The biographical dictionary of management. Bristol : Thoemmes Press, 2001, v. 1, p. x.

WORTHY, J. C. From practice to theory: odyssey of a manager. In: BEDEIAN, A. G. Management laureates: a collection of autobiographical essays. Greenwich : JAI Press, v. 3, 1993, p. 385-6.

WORTHY, J. C. Brushes with history: reflections of a many-favored life. Chicago : Thompson-Shore, 1998.

WRIGHT, D. B. e NUNN, J. A. Similarities within event clusters in autobiographical memory. Applied Cognitive Psychology, v. 14, n. 5, 2000, p. 479-89.

\section{Eric W. Ford}

Professor de Políticas de Saúde e Administração na Pennsylvania State University. Ph.D. pela University of Alabama

E-mail: eford@psu.edu

\section{W. Jack Duncan}

Professor de Administração na University of Alabama. Ph.D. pela Louisiana State University.

E-mail: jduncan@uab.edu

Endereço: University of Alabama at Birmingham. 207D BEC, $15303^{\text {rd }}$ Avenue South. Birmingham, AL. 35294-4460.

\section{Arthur G. Bedeian}

Prof. na Louisiana State University. DBA pela Mississippi State University.

E-mail: abede@mail071.Isu.edu

\section{Peter M. Ginter}

Prof. de Administração na University of Alabama. Ph.D. em Teoria Organizacional pela University of North Texas.

E-mail.: pginter@uab.edu

\section{Matthew Rousculp}

Pesquisador da Eli Lilly and Company. Ph.D. em Administração de Serviços de Saúde pela University of Alabama

E-mail: rousculp_matthew_d@lilly.com

\section{Alice M. Adams}

Doutoranda na University of Alabama

E-mail: aadams@alumni.duke.edu 